\title{
OTIMIZAÇÃO DO LAYOUT DE MARCENARIAS NO SUL DO ESPÍRITO SANTO BASEADO EM PARÂMETROS ERGONÔMICOS E DE PRODUTIVIDADE ${ }^{1}$
}

Nilton César Fiedler ${ }^{2}$, Fernando Bonelli Wanderley ${ }^{3}$, Marcelo Nogueira $^{2}$, José Tarcísio da Silva Oliveira ${ }^{2}$, Pompeu Paes Guimarães ${ }^{3}$ e Rafael Tonetto Alves ${ }^{3}$

\begin{abstract}
RESUMO - Este estudo foi realizado em três marcenarias no sul do Estado do Espírito Santo, com o objetivo de analisar o layout e propor mudanças que otimizem o funcionamento harmônico entre o local de trabalho e o trabalhador, considerando-se fatores ergonômicos, fluxo de produção e produtividade. A coleta de dados foi feita analisando-se as condições do ambiente de trabalho (clima, ruído, iluminação) e aplicando uma entrevista para avaliar as condições gerais e de segurança no trabalho. O layout foi avaliado por medições, observação da sequência de trabalho nas máquinas e aplicação do software AutoCAD 2000. Os resultados indicaram que o Índice de Bulbo Úmido e o Termômetro de Globo estavam de acordo com a Norma Regulamentadora $\mathrm{n}^{\circ}$ 15 (atividade moderada), sendo de $26,38^{\circ} \mathrm{C}$, em média. Os níveis médios de ruído foram de $87,48 \mathrm{~dB}$ (A), acima do permitido para uma jornada de $8 \mathrm{~h}$ diárias (NR 15). A luminosidade média, encontrada em duas marcenarias, ficou acima da faixa de iluminação mínima recomendada para esse trabalho de maquinarias (NBR 5413/92). Todas as marcenarias tinham disposição desordenada do maquinário em razão da sequência lógica de trabalho, presença de pilastras e resíduos na área útil e de passagem, piso desnivelado, falta de rampas para acesso aos galpões, manutenção de máquinas e equipamentos de forma incorreta, falhas no telhado e ausência de bancadas para facilitar a adoção de uma melhor postura durante o manuseio das peças.
\end{abstract}

Palavras-chave: Ergonomia florestal, análise de produtividade e layout de marcenarias.

\section{LAYOUT OPTIMIZATION OF JOINERIES IN SOUTHERN ESPIRITO SANTO STATE BASED ON ERGONOMIC AND PRODUCTIVITY PARAMETERS}

\begin{abstract}
This research was carried out in three joineries in southern Espírito Santo State to analyze their layout and consider changes to optimize the harmonious functioning between workplace and worker, considering ergonomic factors, production flow and productivity. Data bases were analyzed taking into account the work environment (climate, noise, illumination), through interviews to evaluate general and work safety conditions. The layout was evaluated by measurements, machine sequence observations and AutoCAD 2000 software application. The results obtained showed that the Humid Bulb Globe Thermometer Index complied with Prescribed Norm no. 15 (moderate activity), around $26.38^{\circ} \mathrm{C}$ on average. The average noise levels were $87.48 \mathrm{db}(\mathrm{A})$, above the level allowed for an 8-hour working day (NR 15). Average luminosity, found in two joineries, was also above the minimum range of illumination recommended for machinery work (NBR 5413/ 92). All joineries had their machineries disorderly placed in function of the logical sequence of work, presence of pilasters and residues in the walk-through and working areas, unleveled floor, no ramps for access to the warehouses, incorrect machinery and equipment maintenance, roof flaws and absence of benches that would facilitate adopting a better posture when working.
\end{abstract}

Keywords: Ergonomic forest, productivity analysis and joineries' layout.

\footnotetext{
${ }^{1}$ Recebido em 17.09.2007 e aceito para publicação em 26.01.2009.

${ }^{2}$ Departamento de Engenharia Florestal da Universidade Federal do Espírito Santo (UFES). E-mail: <fiedler@ pesquisador.cnpq.br>

${ }^{3}$ Engenheiro florestal - DEF/CCA/UFES 29500-000 Alegre-ES.
} 


\section{INTRODUÇÃO}

A indústria de madeira serrada alcançou, ao longo das últimas décadas, alto nível de desenvolvimento e de comprometimento com outras indústrias de base florestal, objetivando buscar maior eficiência na qualidade dos produtos e racionalização na utilização da matériaprima. À medida que as serrarias se especializam na busca de melhores produtos e maiores rendimentos, as indústrias de beneficiamento (entre estas, as marcenarias) melhoram a qualidade e reduzem seus custos de produção.

O desequilíbrio entre oferta e demanda dado pela escassez da matéria-prima e pelo crescimento do emprego e da industrialização da madeira (aglomerado, compensado, MDF, HDF, OSB etc.), principalmente das espécies de reflorestamento e derivados, vem gerando a necessidade de inovações tecnológicas para a utilização racional da madeira, tanto em aspectos de qualidade (produtos com melhor acabamento superficial) quanto econômicos (conversão ou rendimento de madeira serrada e energia para o processamento).

Tendo em vista a escassez de madeira para serraria em diversas regiões do país (o que muitas vezes implica chegada de matérias-primas de regiões diferentes, com idades distintas e condições de crescimento específicas), geralmente nos pátios das indústrias de madeira serrada se encontra grande variedade de espécies com classes diamétricas diferenciadas. Associado a isso, em função da flexibilidade dessas indústrias em atenderem a variados mercados, a gama de produtos serrados, muitas vezes, torna-se ampla.

O rendimento de madeira serrada, por exemplo, pode ser afetado pela interação dos vários fatores relacionados à madeira, ao maquinário de corte e ao processo, os quais não devem ser analisados isoladamente. Em relação ao processo, o fator humano muitas vezes é esquecido e até mesmo negligenciado, por displicência ou por falta de conhecimento das necessidades de adequação do trabalho ao funcionário (SILVA et al., 2002; FIEDLER et al., 2003).

Uma condição de trabalho em que a ergonomia do processo não é observada leva a um baixo rendimento do trabalhador e, consequentemente, da produção final. $\mathrm{O}$ inadequado posicionamento das máquinas e equipamentos no processo de produção de uma marcenaria gera perdas na produtividade, e a saúde do trabalhador pode ser severamente prejudicada.
Comumente ocorrem fadigas por sobrecarga física, com as posturas inadequadas gerando dores no sistema musculoesquelético do trabalhador, tendo como consequência a redução do ritmo de trabalho e de raciocínio, o que pode levar a erros e, até mesmo, ao seu afastamento por doenças ocupacionais. Segundo Silva et al. (2006), os parâmetros antropométricos dos trabalhadores devem ser levados em consideração no dimensionamento de postos de trabalho nas marcenarias. Assim, as alturas e demais dimensões das bancadas, máquinas e locais de depósito de madeira devem adequarse à compleição física dos trabalhadores.

Outra fonte de tensão no trabalho é a condição ambiental desfavorável como excesso de calor, umidade, ruído e vibração, incluindo-se também luminosidade imprópria, além da exposição a gases, fuligens e poeiras. Esses fatores, segundo Fiedler et al. (2006), causam desconforto, aumentam o risco de acidentes e podem provocar danos consideráveis à saúde, sendo grande parte das lesões decorrentes do risco ergonômico do tipo trauma cumulativo, ou seja, o trabalhador somente irá perceber seus efeitos deletérios depois de alguns anos numa situação de trabalho que, a princípio, o mesmo considerava até cômoda.

Uma das maneiras de minimizar esses problemas é a formação de um layout ótimo para cadeia produtiva. Definidos os equipamentos necessários para a produção desejada, deve ser feito um estudo criterioso sobre a forma de disposição e localização desses equipamentos. Para um bom fluxo de produção, os equipamentos devem estar dispostos em linha reta, evitando-se ao máximo mudanças de fluxo em ângulos, além de evitar o retrocesso das peças.

De acordo com Olivério, citado por Castro (2003), o estudo do layout é de fundamental importância para assegurar perfeito entrosamento interno e funcionamento harmônico do ambiente. Segundo Fiedler et al. (2003), um ambiente de trabalho disposto de forma ideal garante a estética do local e um fluxo racional do processo.

A locação dos equipamentos quanto a sequência lógica de produção, níveis de iluminância adequada para cada processo, distâncias mínimas necessárias entre máquinas, áreas destinadas a resíduos e locais necessários para pausas, entre outros fatores, favorece o ambiente de trabalho, trazendo motivação e qualidade de vida ao trabalhador, e pode gerar, assim, maior produtividade. 
O estudo de parâmetros que afetam o rendimento da madeira serrada é de extrema importância não só para o aumento do rendimento de madeira, mas para o uso racional deste recurso renovável que se torna cada vez mais escasso.

Esta pesquisa teve como objetivo a análise do layout de marcenarias no sul do Estado do Espírito Santo, com a proposição de mudanças que otimizem o funcionamento harmônico entre o local de trabalho e o trabalhador, considerando-se a melhoria do fluxo de produção, fatores ergonômicos e de produtividade.

\section{MATERIAL E MÉTODOS}

\subsection{Região de estudo}

A pesquisa foi desenvolvida em três marcenarias (empresas fabricantes de móveis a partir de madeira) nos Municípios de Alegre e Jerônimo Monteiro, no sul do Estado do Espírito Santo, no período de agosto de 2006 a julho de 2007. Essas empresas foram escolhidas por possuírem fluxo contínuo de produção.

\subsection{População e amostragem}

O número mínimo de repetições utilizadas para o ambiente de trabalho, neste estudo, foi estabelecido com base em uma amostragem-piloto, analisada com uso da seguinte fórmula, proposta por Conaw (1977):

$$
\mathrm{n} \geq\left(\mathrm{t}^{2} * \mathrm{~s}^{2}\right) / \mathrm{e}^{2}
$$

em que $\mathrm{n}=$ número de amostras ou repetições; $\mathrm{t}=$ valor tabelado a 5\% de probabilidade (distribuição t, de Student); $\mathrm{s}=$ desvio-padrão da amostra; e = erro admissível a $5 \%$.

\subsection{Caracterização das empresas e avaliações qualitativas dos locais de trabalho}

A caracterização das empresas procedeu-se através de um questionário aplicado em forma de entrevista aos gerentes. Pesquisaram-se: (i) o número de funcionários; (ii) a matéria-prima utilizada; (iii) as principais máquinas envolvidas no processo de fabricação de móveis; (iv) a sequência normalmente utilizada na produção; (v) a qualidade da manutenção das máquinas; e (vi) o destino e forma de deposição dos resíduos.

A avaliação referente ao layout realizou-se por estudos individuais, em que a abordagem dos problemas ocorreu através da pesquisa qualitativa, que visou analisar e correlacionar os fatos através de entrevistas com o uso de questionário semiestruturado, observações e registros e, também, com a pesquisa bibliográfica e documental para recolher, analisar e interpretar informações já existentes sobre o assunto e o ambiente de estudo.

\subsection{Sistema de produção avaliado}

\subsubsection{Máquinas avaliadas}

As máquinas envolvidas no processo de fabricação de móveis e selecionadas na pesquisa para este estudo estão listadas na Tabela 1. Nessas empresas, observouse que o encaminhamento do ciclo de produção começava pela serra de destopo e serra circular, em que se determinavam a largura e comprimento da peça, passando, posteriormente, pela desempenadeira e desengrossadeira, nivelando e dimensionando sua espessura, respectivamente. As outras máquinas atuavam no processo de acabamento, realizando molduras e ranhuras como a tupia, eliminando imperfeições e asperezas (lixadeira), além de furos e cavas, como observado na máquina furadeira horizontal. Na Figura 1 são mostradas as máquinas analisadas.

\subsubsection{Avaliação ergonômica do sistema de produção}

Para o estudo ergonômico do trabalho, avaliaramse as condições climáticas do ambiente de trabalho com o uso de termômetro digital de Índice de Bulbo Úmido Termômetro de Globo (IBUTG) da marca METROSONICS, modelo HS - 3600. As leituras foram feitas de hora em hora, sendo a primeira leitura às 8 h e a última, às $17 \mathrm{~h}$, no mês de junho.

Os níveis médios de ruídos ( $\mathrm{dB}(\mathrm{A})$ ) foram medidos com o uso de um decibelímetro digital de marca Instrutherm, modelo DEC - 460, com sensor instalado ao nível do ouvido do trabalhador, de acordo com a Norma Regulamentadora No 15 (NR 15), do Ministério do Trabalho e Emprego - Atividades e Operações Insalubres (Segurança e Saúde no Trabalho, 2006), feitos em intervalos de 20 seg durante a jornada de trabalho diária, durante quatro meses.

A iluminância foi medida com o uso de um luxímetro digital portátil de marca TES, modelo TES1332A, sendo as leituras feitas sistematicamente a cada 15 min e realizadas em vários pontos da marcenaria, durante quatro meses de coleta. $\mathrm{O}$ aparelho foi colocado na altura dos postos de trabalho, com a fotocélula em plano horizontal, conforme preceitua a norma técnica NBR 5413/92 da ABNT, que trata de iluminação de interiores.

R. Árvore, Viçosa-MG, v.33, n.1, p.161-170, 2009 
Tabela 1 - Descrição técnica das máquinas avaliadas

Table 1 - Technical description of the evaluated machines

\begin{tabular}{ll}
\hline Máquinas & Descrição \\
\hline Serra de destopo & Utilizada para destopar e esquadrilhar madeira. \\
Serra circular & $\begin{array}{l}\text { Utilizada para serrar madeira ou derivados em cortes retos, por meio de uma serra circular dentada } \\
\text { acoplada a uma mesa de corpo fixo. }\end{array}$ \\
Desempenadeira & Utilizada para nivelar a superfície da peça. \\
Desengrossadeira & $\begin{array}{l}\text { Visa dimensionar a espessura das peças. Utilizada também para aplainar. Constituída por navalhas } \\
\text { e dois rolos de alimentação que funcionam automaticamente. Ao nível da mesa, estão dispostos } \\
\text { outros dois rolos lisos que servem para o deslize da madeira. }\end{array}$
\end{tabular}

Serra de fita

Possui versatilidade de trabalho muito grande, podendo realizar quaisquer tipos de cortes retos ou irregulares, como círculos, ondulações etc. Também, pode-se utilizá-la para o corte de materiais muito espessos, difíceis de serem cortados na serra-circular.

Tupia

Utilizada para fazer molduras, rebaixamentos, ranhuras, perfis e canais. Composta por uma base de ferro na qual se apoia um tampo, no centro do qual se encontra um eixo onde se prendem as ferramentas de corte, que giram com alta velocidade (4.000 a $8.000 \mathrm{rpm})$.

Lixadeira de cinta Acabamentos de superfícies planas ou curvas. Elimina imperfeições e asperezas, para que a peça possa receber o acabamento final. Compõe-se de duas colunas ligadas entre si por uma cinta de lixa, entre as quais existe uma mesa fixa onde é apoiada a peça de madeira.

Furadeira horizontal Utilizada para fazer furos e cavas em peças de madeira e encaixes de espigas ou cavilhas.

Respigadeira Produz espigas redondas, retangulares e inclinadas para um perfeito encaixe em cavas produzidas pela furadeira. A máquina possui duas mesas porta-peças que permitem regulagens de ângulo, inclinações frontal, lateral e do guia de encosto da peça.

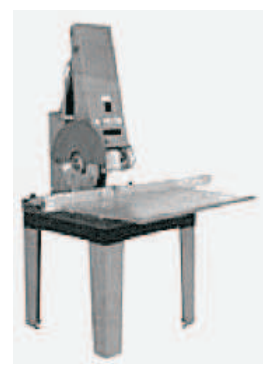

A

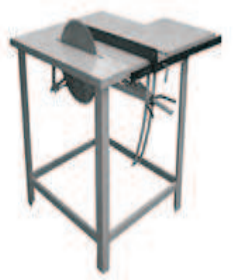

B

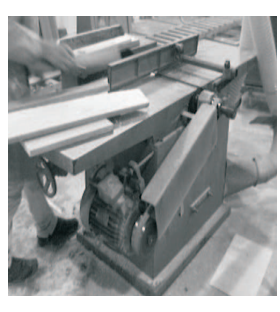

C

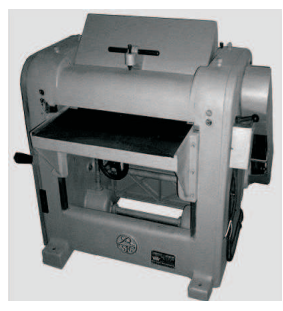

D

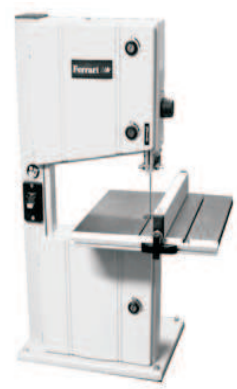

$\mathrm{E}$

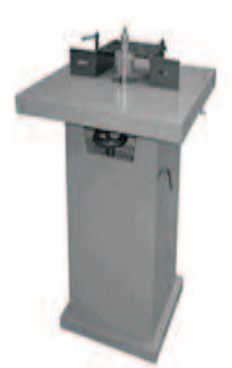

$\mathrm{F}$

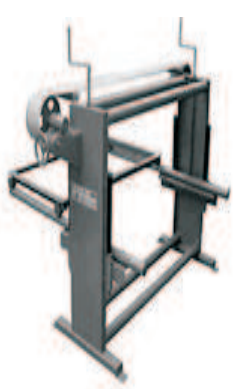

G

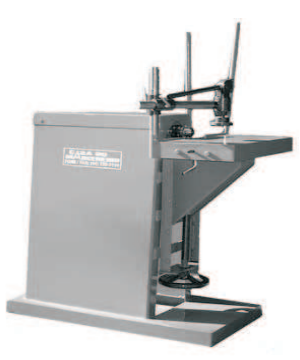

$\mathrm{H}$

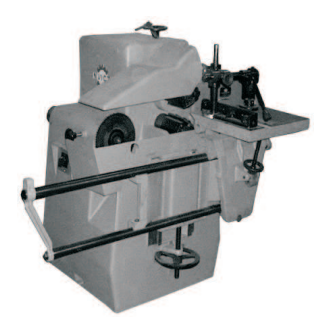

I

Figura 1 - Máquinas utilizadas no ciclo de trabalho nas marcenarias (A: serra de destopo; B: serra-circular; C: desempenadeira; D: desengrossadeira; E: serra de fita; F: tupia; G: lixadeira de cinta; H: furadeira horizontal; e I: respigadeira).

Figure 1 -Machines used in the work cycle at the joineries (A: cutter, B: buzzy saw, C: smoother, D: planer, E: tape saw, $F$ : shaper, G: sander; H: horizontal boring machine; and I: mortiser). 


\subsubsection{Avaliação do Layout das marcenarias}

Para a otimização do processo produtivo das marcenarias, os postos de trabalho foram dimensionados e as máquinas, alocadas para a confecção de plantas baixas das empresas objeto desta pesquisa. Além disso, foi avaliada em cada empresa a sequência lógica de trabalho dos operadores por máquina avaliada em relação ao seu posicionamento no galpão. Essas análises foram utilizadas para uma proposta de intervenção e elaboração de layout otimizado, respeitando as especificidades do fluxo de produção. Para essa análise, foi utilizado o software AutoCAD 2000.

\section{RESULTADOS E DISCUSSÃO}

\subsection{Amostragem estatística}

O número mínimo de amostras de níveis de ruído $(\mathrm{dB}(\mathrm{A}))$ necessários para melhor intensidade amostral foi calculado em cada máquina analisada, e apresentase na Tabela 2. Em relação à iluminância e às condições ambientais (IBUTG), não se calculou um número mínimo de amostras devido à ocorrência de variação brusca nas áreas em que as máquinas estavam dispostas e, até mesmo, sujeitas à incidência direta do sol.

\subsection{Caracterização das empresas e avaliações qualitativas dos locais de trabalho}

As empresas são classificadas como de pequeno porte (microempresas), utilizando-se pequeno quadro de funcionários (menos de 20) para realização de todas as atividades da marcenaria.

Todas as empresas analisadas empregam quanto à tecnologia usada no processo de fabricação, máquinas e sequências semelhantes. Em relação à matéria-prima, utilizam-se principalmente madeira maciça (espécies variadas) e MDF (medium density fiberboard), trabalhando sob a forma de encomenda, atendendo, principalmente, à região Sul do Espírito Santo.

As marcenarias não possuíam locais apropriados para as refeições dos funcionários e também não disponibilizavam almoço. Foram fornecidos equipamentos de proteção individual para os operários, entre eles os mais usados eram os protetores auriculares observados, mesmo assim, em poucos trabalhadores. A tupia foi considerada unanimemente a máquina mais perigosa e a que causa maior medo, seguida pela desempenadeira e serra-circular.

O transporte de matéria-prima dentro das marcenarias era feito pelos próprios trabalhadores, que em geral executavam todas as funções para a produção dos móveis, operando todas as máquinas. A sequência lógica de fabricação dos produtos começava pela serra de destopo, serra-circular, desempenadeira e desengrossadeira, respectivamente. Posteriormente, as peças passam pela tupia, lixadeira de cinta, serra de fita, furadeira horizontal e respigadeira aleatoriamente, dependendo do acabamento necessário para o móvel. O esmeril era utilizado para afiação de discos das máquinas e de ferramentas auxiliares.

Em relação ao ambiente de trabalho, a variação climática aumenta ou diminui conforme a variação do sol. A média do IBUTG encontrada foi de $26,38^{\circ} \mathrm{C}$, e com esses índices o trabalho pode ser realizado sob condições seguras em todas as empresas, favorecendo o rendimento e a produtividade.

Tabela 2 - Número mínimo de repetições, segundo a amostragem estatística, para os níveis de ruído dB (A) Table 2-Minimum number of repetitions according to statistical sampling for noise level dB(A)

\begin{tabular}{lcccc}
\hline & Ttab & Desvio-padrão & Média (dB(A)) & n Coletado \\
\hline Serra de destopo & 2,021 & 3,608 & 94,790 & 42,000 \\
Serra circular & 1,960 & 5,689 & 88,713 & 520,000 \\
Desempenadeira & 1,960 & 3,132 & 88,354 & 614,000 \\
Desengrossadeira & 1,960 & 4,232 & 87,427 & 327,000 \\
Serra de fita & 2,042 & 6,508 & 80,068 & 31,000 \\
Tupia & 1,980 & 4,833 & 88,900 & 129,000 \\
Lixadeira de cinta & 1,960 & 2,720 & 85,825 & 691,000 \\
Furadeira horizontal & 2,000 & 2,769 & 81,104 & 5,600 \\
Respigadeira & 2,042 & 5,110 & 88,438 & 53,000 \\
\hline
\end{tabular}

Obs.: Ttab - "t" tabelado segundo tabela de Student; n coletado - número de amostras coletadas; e n min - número mínimo de amostras necessárias. 


\subsection{Sistemas de produção}

Por apresentarem formas de layouts diferentes devido à composição do galpão, área útil e localização das máquinas, os problemas identificados e as soluções propostas em cada marcenaria analisada serão apresentados de forma individualizada. Na Tabela 3, encontra-se a legenda de identificação das máquinas e áreas nas plantas de layout.

\subsubsection{Marcenaria 1}

Apresentou iluminação média de 717,03 Lux, estando acima da faixa de iluminação mínima recomendada pela NBR 5413/92 de 500 Lux (VENTUROLI, 2002). O nível médio de ruído encontrado foi de $87,65 \mathrm{~dB}$ (A), apresentando-se acima do limite recomendado pela legislação NR15 para uma jornada de 8 h diárias, reduzindo, assim, o tempo de trabalho para 5 h e 53 min, sem o uso de protetores auriculares. Devido ao reduzido espaço disponível para trabalho, a dificuldade de movimentação de peças foi um dos fatores observados sobre a composição atual do layout, assim como: (i) a falta de cavaletes no interior da marcenaria; (ii) máquinas distantes do depósito de matérias-primas; (iii) resíduos em excesso; (iv) lâmpadas mal distribuídas e insuficientes para a continuação do trabalho após o pôr-do-sol; (v) pilastras interferindo na área útil; (vi) goteiras no galpão de armazenagem de madeira; (vii) local inapropriado para guardar ferramentas e equipamentos de uso constante; (viii) manutenção de equipamentos feita de forma corretiva; (ix) ausência de exaustor na máquina lixadeira de cinta; $\mathrm{e}(\mathrm{x})$ posicionamentos inadequados de algumas máquinas, estando próximas a locais de intensa movimentação, atrapalhando o deslocamento de peças, sendo um agravante para acidentes. A Figura 2 ilustra o layout da marcenaria 1.

As seguintes alterações são propostas: (i) utilização de cavaletes e bancadas para facilitar o transporte e manuseio das peças de madeira dentro da marcenaria e nas máquinas; (ii) retirada de resíduos do galpão e aqueles que atrapalham o tráfego no pátio, posteriormente depositados em um local específico; (iii) aumento no número de lâmpadas e melhor distribuição, melhorando as condições de iluminação após o pôrdo-sol ou em dias chuvosos; (iv) organização adequada de ferramentas e equipamentos de uso contínuo; (v) colocação de um sistema de exaustor na máquina lixadeira de cinta; (vi) manutenção dos equipamentos de forma preventiva; e (vii) aumento da largura do beiral e reforma do telhado.

R. Árvore, Viçosa-MG, v.33, n.1, p.161-170, 2009
Com relação à ventilação, não foram encontrados problemas. Para o acesso de pessoas e materiais, recomenda-se a construção de uma rampa ligando o galpão de armazenamento ao galpão de máquinas, aumentando, com isso, o acesso e o espaço útil destes. Conjuntamente, propõe-se uma nova organização na sequência de utilização das máquinas, considerando os níveis de iluminação e ruído e a chegada e partida de matéria-prima, evitando locais de constante acesso de pessoas, conforme ilustrado na Figura 3.

Com o novo layout : (i) a disposição das máquinas na periferia da marcenaria facilita o transporte manual de cargas; (ii) melhora a iluminância em cada máquina, pois aproveita a iluminação natural do dia; (iii) inclui a área de armazenamento de madeiras no galpão de máquinas, o que agiliza o manuseio da madeira serrada armazenada e das peças produzidas; (iv) melhora o fluxo de pessoas; e (v) reduz o tempo de caminhamento entre máquinas e encurta o processo produtivo.

Tabela 3 - Legenda para as plantas baixas do layout Table 3 - Legend for the layout of the joineries

\begin{tabular}{lccc}
\hline$N^{\circ}$. & Referência & $N^{\circ}$ & Referência \\
\hline 1 & Serra de Destopo & 11 & Madeira empilhada \\
2 & Serra Circular & 12 & Depósito de ferramentas \\
3 & Desempenadeira & 13 & Sala de verniz \\
4 & Desengrossadeira & 14 & Sala de acabamento \\
5 & Tupia & 15 & Prensa \\
6 & Lixadeira de Cinta & 16 & Máquina de \\
& & & modelagem de fórmica \\
7 & Serra de Fita & 17 & Banheiro \\
8 & Furadeira Horizontal & 18 & Escritório \\
9 & Esmeril & 19 & Desdobro \\
10 & Respigadeira & 20 & Projeção do beiral \\
\hline
\end{tabular}

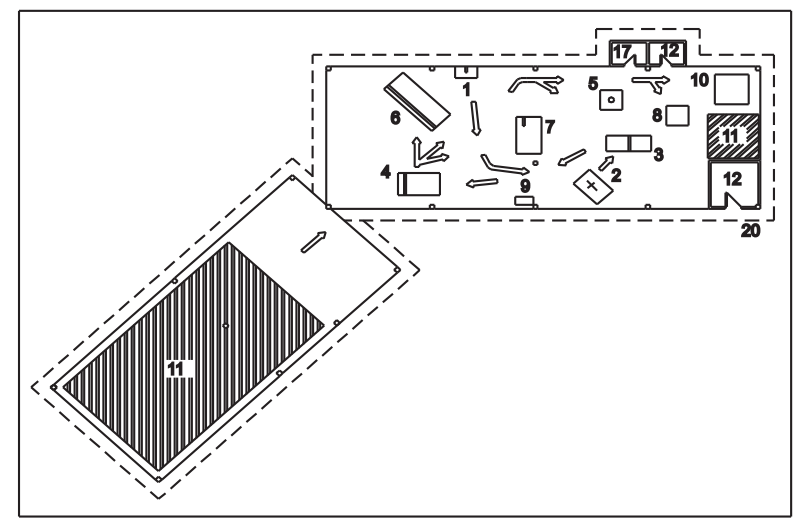

Figura 2 - Layout atual da marcenaria 1. Figure 2-Current layout of the joinery 1. 


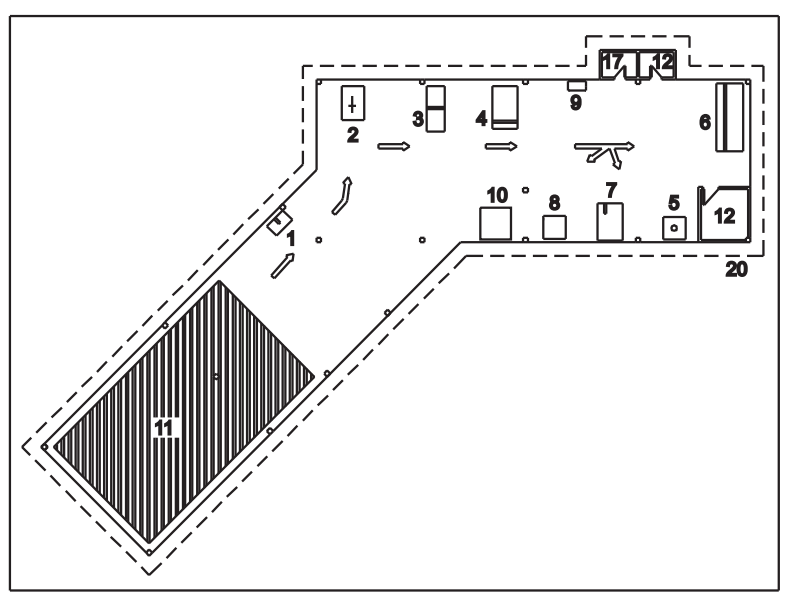

Figura 3 - Proposição de layout para a marcenaria 1. Figure 3 -Suggestion of layout for the joinery 1.

\subsubsection{Marcenaria 2}

A iluminação média encontrada foi de 211,73 lux, estando muito abaixo do limite mínimo recomendado pela NBR 5413/92 para a atividade, que é de 500 lux. O nível médio de ruído encontrado foi de 87,95 dB (A), o que significa que o trabalhador nesse caso tem exposição máxima diária permitida de $5 \mathrm{~h}$ e $38 \mathrm{~min}$, sem o uso de protetores auriculares, segundo a NR15. O carregamento de materiais é feito de forma incorreta, em que o funcionário pega do chão a matéria-prima a ser utilizada e desloca-se carregando-a sem nenhum tipo de adequação. Outros fatores observados sobre a composição atual do layout foram: (i) ventilação deficiente; (ii) localização inadequada da madeira empilhada em relação ao desdobro; (iii) disposição desordenada do maquinário; (iv) presença de resíduos na área útil e de passagem; (v) os resíduos gerados após a passagem da madeira pela lixadeira de cinta retornam ao galpão; (vi) o telhado é baixo e inadequado para o tipo de empresa; (vii) o sistema elétrico é deficiente para a exigência de potência do maquinário; (vii) a manutenção dos equipamentos é de forma corretiva; (ix) a caixa d'água, com vazamento, está localizada acima do local de armazenamento das madeiras; (x) o galpão possui áreas construídas inadequadamente, como banheiro pequeno, piso desnivelado e falhas no telhado, permitindo que alguns equipamentos e parte da matériaprima recebam chuva e insolação direta; e (xi) a sala de verniz não se encontra separada fisicamente de outras áreas do galpão. Na Figura 4, observa-se o estado atual da marcenaria 2.

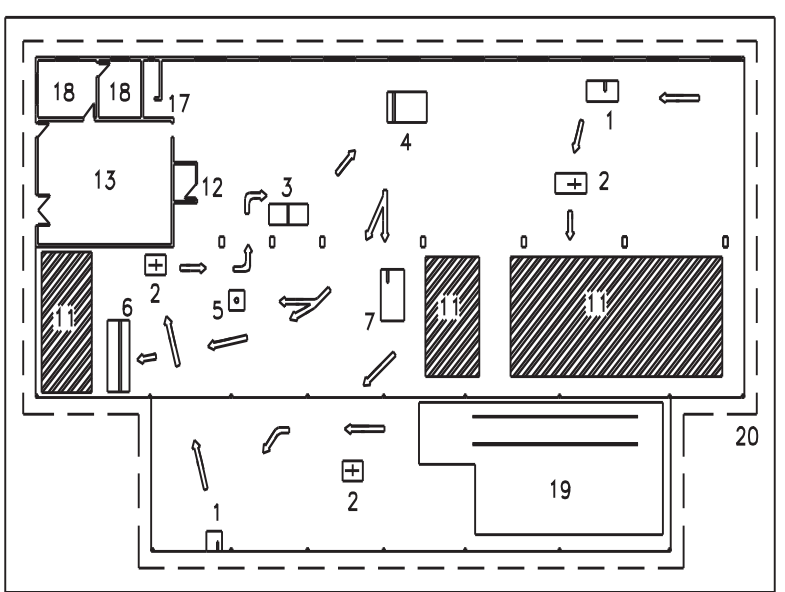

Figura 4 - Layout atual da marcenaria 2.

Figure 4-Current layout of the joinery 2.

Também foram sugeridas alterações no posicionamento dos equipamentos, na forma de trabalho e no padrão do galpão, sendo estas: (i) elevação das aberturas laterais para favorecer a entrada de luz e ventilação; (ii) aumento no número, potência e distribuição das lâmpadas; (iii) reorganização da armazenagem de matéria-prima proveniente do desdobro, localizando-as próximas a esta; (iv) limpeza constante da área do galpão e não somente quando houver concentração em demasia de resíduos, idealizando também uma área adequada para sua deposição; (v) utilização de cavaletes e bancadas para facilitar o transporte e manuseio das peças de madeira dentro da marcenaria e nas máquinas; (vi) troca da rede elétrica, utilizando-se fiação e componentes elétricos adequados ao consumo energético requerido; (vii) aumento da frequência de manutenção das máquinas, ferramentas e equipamentos, realizando-as de forma preventiva; (viii) troca do telhado e aumento do beiral, minimizando a insolação direta e chuvas nas partes laterais da área do galpão; (ix) nivelamento do piso do galpão; (x) construção de rampas de acesso; e (xi) aumento da área do banheiro. A colocação de um sistema de exaustão eficiente na sala de verniz e na lixadeira de cinta diminuirá a inalação de gases e poeiras dentro da empresa.

Conjuntamente, propõe-se uma nova organização na sequência de utilização das máquinas, levando em consideração a sequência otimizada de trabalho, os níveis de iluminação e ruído, o espaço útil do galpão e a localização de pilastras e paredes. O caminhamento do layout otimizado ilustrado na Figura 5 ficou sinuoso devido à impossibilidade de mudança na estrutura física já construída, limitando a agilidade do processo produtivo. 


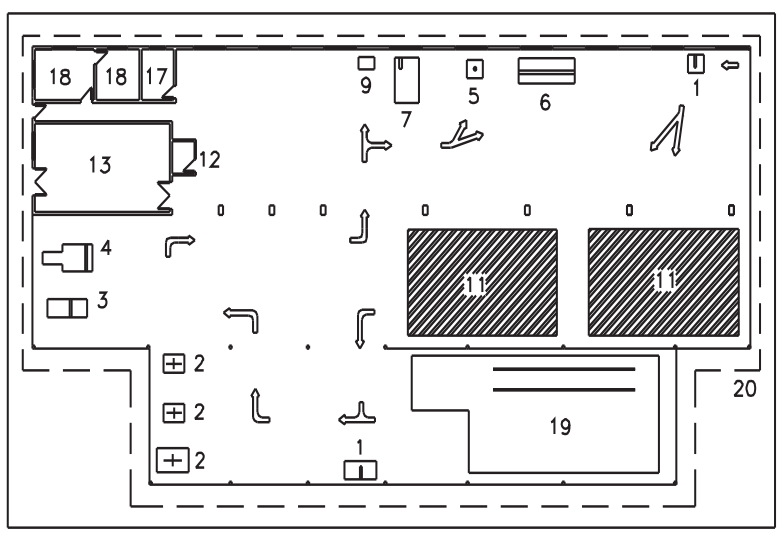

Figura 5 - Proposição de layout para a marcenaria 2. Figure 5-Suggestion of layout for the joinery 2.

\subsubsection{Marcenaria 3}

Apresentou iluminação média de 1.120,89 lux, estando dentro da faixa de iluminação recomendada pela NBR 5413/92 para a atividade (superior a 500 lux). O nível médio de ruído de 85,24 dB (A) está acima do permitido pela NR 15 (SEGURANÇA E MEDICINA DO TRABALHO, 2006), para uma jornada de trabalho de $8 \mathrm{~h}$ diárias, como diagnosticado também nas outras empresas, podendo o trabalhador ficar exposto $7 \mathrm{~h}$ e 48 min diariamente, sem comprometer o seu sistema auditivo. Outros fatores observados sobre a composição atual do layout foram: (i) dificuldade de movimentação de peças devido ao reduzido espaço disponível para trabalho nos maquinários, uma vez que parte da área é destinada para a montagem de móveis; (ii) galpão com áreas construídas inadequadamente, permitindo que equipamentos e matéria-prima recebam chuva e insolação direta; (iii) beiral do telhado com largura insuficiente; e (iv) área para aplicação de tintas, vernizes e acabamentos apresenta ventilação e iluminação deficientes, sem sistema de exaustão, deixando o trabalhador em contato direto e contínuo com gases tóxicos. O layout atual da marcenaria 3 está ilustrado na Figura 6.

Após análise, as recomendações propostas foram: (i) reduzir a insolação sobre as máquinas e, consequentemente, sobre os trabalhadores, com ampliação da largura do beiral do telhado, pois no horário compreendido entre 10 e 16 h a radiação solar é crítica, implantando-se também toldos móveis em locais onde necessários; (ii) construção de um banheiro; e (iii) aumento na potência das lâmpadas, colocação de janelas e sistemas de exaustão nas salas de verniz e acabamento. A serra de destopo nessa empresa é móvel, sendo utilizada principalmente para esquadrilhar peças de
MDFe, portanto, localizada próximo do local de montagem dos móveis. A sequência de utilização das máquinas foi reorganizada, levando-se em consideração os níveis de iluminação e ruído, chegada e partida de matériasprima, espaço útil do galpão e localização de pilastras, como ilustra a nova proposta de layout (Figura 7).

\subsubsection{Análise integrada das marcenarias}

Os postos de trabalho das empresas apresentaram média do IBUTG de $26,38^{\circ} \mathrm{C}$, sendo perfeitamente tolerado pelo organismo humano para a realização das tarefas de fabricação de móveis numa jornada de $8 \mathrm{~h}$. Quanto ao ruído, para esse tipo de atividade moderada os níveis médios foram de 87,48 dB (A), ficando acima do permitido para uma jornada de 8 h diárias, de acordo com a NR 15 . O ruído no ambiente é aditivo; assim, quanto maior o número de máquinas em uso, maior o ruído médio produzido e, portanto, passível de prejudicar a concentração mental e certas tarefas que exigem atenção ou velocidade e precisão de movimentos. Segundo Vieira (1997), a maneira mais frequente de solucionar esse problema é o fornecimento de protetores auriculares adequados para os trabalhadores.

A luminosidade média encontrada (683,23 lux) ficou acima da faixa de iluminação mínima recomendada para esse tipo de maquinaria (NBR 5413/92), que deve ser de 500 lux (VENTUROLI, 2002). No entanto, em uma marcenaria e em algumas áreas dos galpões de outras empresas apresentaram escassez de luminosidade e deficiência na circulação de ar. Uma quantidade de luz abaixo do necessário induz à fadiga visual e provoca esforço excessivo para visualização das peças. A introdução de lâmpadas com potência adequada ao local, janelas e vãos de abertura melhorariam esse aspecto ergonômico, diminuindo a concentração de gases e poeiras dentro dos galpões.

A disposição desordenada do maquinário, presença de pilastras e resíduos nas áreas úteis e de passagem, pisos desnivelados e falta de rampas de acesso atrapalham o caminhamento, o transporte manual de matéria-prima e a operação das máquinas nos galpões de produção. Evitando o retrocesso, a mudança de fluxos em ângulos com as peças e a sequência desordenada das máquinas para processamento, ganha-se na racionalização do processo com consequente aumento da produtividade. 
Para diminuir o risco de acidentes, os resíduos gerados devem ser encaminhados para fora do galpão e acondicionados em locais apropriados para futuros destinos. O piso deve ser nivelado e, de preferência, antiderrapante, e os acessos aos galpões devem possuir rampas e nunca degraus. A manutenção das máquinas e equipamentos deveria ser de forma preventiva, mas na realidade ocorre de forma corretiva, levando a um acréscimo do nível de ruído devido ao aumento do atrito entre peças (falta de lubrificação) e o desgaste dos dentes das serras (contato com a matéria-prima). Os galpões possuem falhas no telhado, permitindo que algumas máquinas e parte da matériaprima recebam chuva e insolação direta, exigindo com isso maior esforço visual do operador, já que os olhos humanos precisam de um tempo de recuperação e adaptação ao passarem de um ambiente mais escuro para um mais claro e, ou, vice-versa. A expansão do beiral do telhado é necessária, pois no horário compreendido entre 10 e 16 h a radiação solar é crítica e nociva à saúde. A implantação de toldos móveis também resolve o problema.

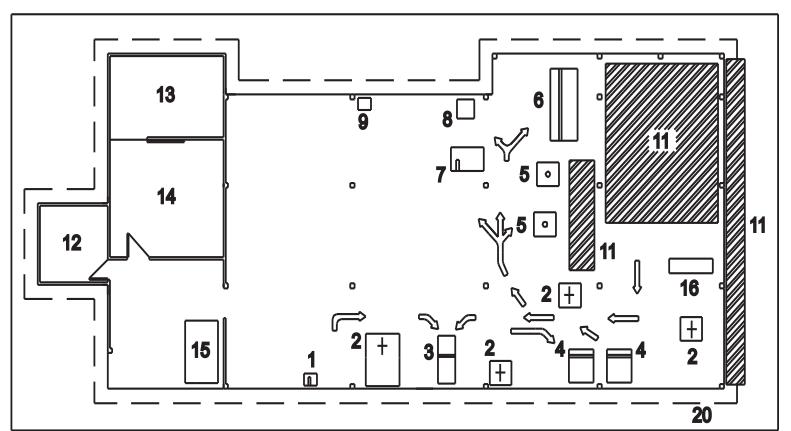

Figura 6-Layout atual da marcenaria 3.

Figure 6-Current layout of the joinery 3.

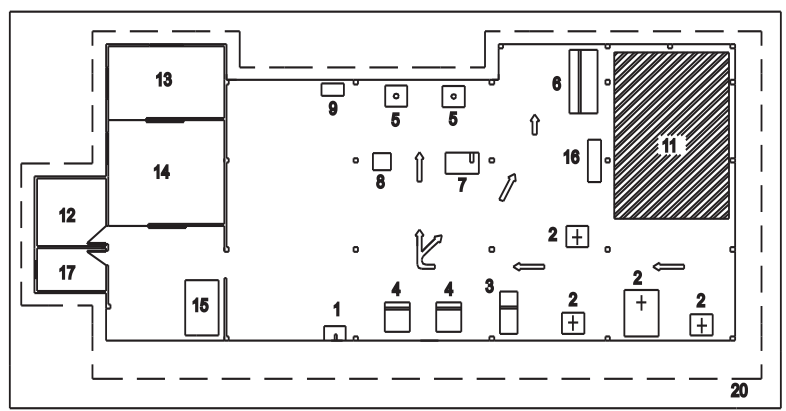

Figura 7 - Proposição de layout para a marcenaria 3. Figure 7 - Suggestion of layout for the joinery 3.

\subsubsection{Aplicação das propostas apresentadas}

Todas as sugestões oferecidas foram discorridas em torno de objeções para que as microempresas pudessem absorver, por inteiro, todas as indicações propostas. Não foram alteradas as áreas dos galpões e suas composições, ponto esse que acarretaria grandes custos aos empreendimentos, mantendo-se, assim, a infra-estrutura e o maquinário originais de cada marcenaria. A simples mudança no posicionamento das máquinas possibilita a transferência do tempo de trabalho disperso em trabalho efetivo, superação de custos decorridos pelas alterações propostas, maior satisfação dos trabalhadores e investimento no binômio conforto/ produtividade. Quanto às propostas sugeridas, os empresários mostraram-se abertos a absorverem esses novos conhecimentos e tecnologia e concordam com as modificações propostas.

\section{CONCLUSÕES E RECOMENDAÇÕES}

De acordo com a coleta de dados relativa ao ambiente de trabalho e layout das três marcenarias, concluise que:

O valor de IBUTG médio encontrado é perfeitamente tolerado por um trabalhador durante uma jornada de trabalho de $8 \mathrm{~h}$.

O nível médio de ruído apresentado em todas as empresas estava acima do permitido pela legislação para uma jornada de $8 \mathrm{~h}$ diárias, portanto é necessário que os trabalhadores utilizem protetores auriculares se não for possível reduzir o ruído na fonte.

A luminosidade média encontrada em uma das marcenarias ficou abaixo da faixa de iluminação mínima recomendada pela NBR 5413/92 (500 lux). Nas demais, apesar de médias acima do mínimo necessário, algumas áreas apresentaram escassez de luminosidade e deficiência na circulação de ar.

Há dificuldade de movimentação de peças devido ao reduzido espaço disponível para trabalho, em razão dos posicionamentos inadequados de algumas máquinas e pilastras.

Nenhuma das marcenarias avaliadas possuía exaustores nas máquinas que produziam resíduos muito finos e em áreas onde se trabalhava com produtos químicos, como colas e tintas.

R. Árvore, Viçosa-MG, v.33, n.1, p.161-170, 2009 
Em todas as empresas avaliadas foi verificada a falta de rampas, desnivelamento do piso dos galpões e telhados inapropriados e com beirais estreitos.

A limpeza dos galpões não era regular, e os resíduos em geral não ficavam depositados em lugares próprios.

Por serem marcenarias de pequeno porte, era inviável a proposta de mudanças drásticas nos padrões de construção dos galpões e na forma de produção, mas a sugestão de alternativas para facilitar o processo de produção e melhorar as condições de trabalho produziriam melhorias significativas no sistema produtivo como um todo.

As recomendações sugeridas para uma nova proposição de layout são:

Manutenção preventiva das máquinas, para redução do ruído e, ou, uso de protetores auriculares como medida curativa.

Implantação de lâmpadas mais potentes e aberturas laterais maiores nos galpões, para aumentar a luminosidade e a circulação de ar.

A dificuldade de movimentação de peças poderia ser sanada através da otimização da sequência de utilização das máquinas.

Instalação de sistemas de exaustores nas máquinas lixadeiras de cinta e nas salas onde se trabalhavam com produtos químicos.

Construção de rampas, nivelamento do piso e reforma do telhado com aumento do seu beiral, para maior rendimento e satisfação do empregado.

\section{REFERÊNCIAS}

CAstro, D. C. Meio Ambiente de

Trabalho e sua implicações no processo produtivo: o caso marcenaria da UFOP. Ouro Preto: Universidade Federal de Ouro Preto, 2003. 89p.
CONAW, P. L. Estatística. São Paulo: Edgard Blucher, 1977. 264p.

FIEDLER, N. C. et al. Análise da exigência física do trabalho em fábricas de móveis no Distrito Federal. Revista Árvore, v.27, n.6, p.879-885, 2003.

FIEDLER, N. C.; RODRIGUES, T. O.; MEDEIROS, M. B. Avaliação das condições de trabalho, treinamento, saúde e segurança de brigadistas de combate a incêndios florestais em unidades de conservação do Distrito Federal. Revista Árvore, v.30, n.1, p.55-63, 2006

FURTADO F., C. P. R. C. Avaliação do rendimento de madeira serrada de Pinus, estudantes de graduação: engenharia. industrial madeireira - UNIPLAC/ Universidade do Planalto Catarinense, Revista da Madeira, v.15,n.88, p.170, 2005.Disponível em www.remade.com.br, acessado em 03/03/2009.

SÃO PAULO (Estado). Segurança e Medicina do Trabalho. 56.ed. São Paulo, Atlas, 2006. 771p. (Manuais de Legislação Atlas, 16).

SILVA, K. R.; SOUZA, A. P.; MINETTI, L. J. Avaliação do perfil de trabalhadores e das condições de trabalho em marcenarias no município de Viçosa-MG. Revista Árvore, v.26, n.6, p.769-775, 2002.

SILVA, K. R. et al. Avaliação antropométrica de trabalhadores em indústrias do pólo moveleiro de UbáMG. Revista Árvore, v.30, n.4, p.613-618, 2006.

VEnturoli, F. Análise ergonômica do ambiente de trabalho em marcenarias do Distrito Federal. Brasília: Universidade de Brasília, 2002. 55p.

VIEIRA, S. D. G. Análise ergonômica do trabalho em uma empresa de fabricação de móveis tubulares. Estudo de casos. Florianópolis: Universidade Federal de Santa Catarina, 1997. 58p. 